\begin{tabular}{|c|l|}
\hline Title & Policy Interaction and Learning Equilibria \\
\hline Author(s) & Kudoh, Noritaka \\
\hline Citation & $\begin{array}{l}\text { Macroeconomic Dynamics, 17(4), 920-935 } \\
\text { https://doi.org/10.1017/S136510051100526 }\end{array}$ \\
\hline Issue Date & 2013-06 \\
\hline Doc URL & http://hdl.handle.net/2115/53069 \\
\hline Rights & ○ Cambridge University Press 2011 \\
\hline Type & article \\
\hline File Information & S1365100511000526a.pdf \\
\hline
\end{tabular}

Instructions for use 


\title{
NOTES
}

\section{POLICY INTERACTION AND LEARNING EQUILIBRIA}

\author{
NoritaKa KUDOH \\ Hokkaido University
}

This note studies fiscal-monetary policy interactions in an endogenous growth model with multiple assets. The "growth-rate Laffer curve" clarifies an important tension between economic growth and government revenue and reveals that higher economic growth does not always finance a larger budget deficit. There are two Pareto-ranked balanced-growth equilibria, which can both be E-stable. Although fiscal policy can eliminate the expectational indeterminacy, it rules out the equilibrium with a higher growth rate and higher welfare. Near the lower bound of the nominal interest rate, an arbitrarily small budget deficit will select the low-growth equilibrium to be the unique E-stable equilibrium.

Keywords: Endogenous Growth, Public Debt, Indeterminacy, E-Stability

\section{INTRODUCTION}

Fiscal-monetary policy interactions determine the level and composition of government liabilities, and thereby influence the course of inflation and economic activity. The literature on policy interaction not only investigates the effects of policies but also explores the uniqueness and stability of equilibrium under a certain policy regime. The basic premise of this extensive literature is that monetary policy alone cannot fully control the paths of the inflation rate and the price level, as fiscal variables such as the public debt and budget deficits have profound impacts on the inflation rate and the price level [Sargent (1999)].

Although many results have been presented in the literature, policy interaction in an endogenously growing economy is a relatively uncharted area of research. Espinosa-Vega and Yip (1999), in an early contribution to this area, studied fiscalmonetary policy interaction in a one-sector endogenous growth model with money and capital. More recently, Kaas and Weinrich (2003) studied an endogenous growth model with money, government bonds, and capital.

\footnotetext{
I thank the associate editor and the referees for their insightful comments and suggestions. I also thank Mariko Yoshida, Toshiji Miyakawa, and seminar participants at Hokkaido University, Hitotsubashi University, Kansai University, Keio University, Kobe University, Osaka University, the JEA Meetings in Hiroshima, and the Mathematical Economics Conference in Kyoto for their helpful comments on an earlier version of this paper. Part of this reserch was financially supported by KAKENHI (Grants 17730140 and 20730125). Address correspondence to: Noritaka Kudoh, Department of Economics, Kita 9 Nishi 7, Kita-ku, Sapporo 060-0809, Japan; e-mail: kudoh@econ.hokudai.ac.jp.
} 
In this note, I study a one-sector endogenous growth model of the AK type that is similar to those of Bencivenga and Smith (1991), Espinosa-Vega and Yip (1999), and Kaas and Weinrich (2003). As in Kaas and Weinrich (2003), there are three assets: money, government bonds, and productive capital. Fiat money is held because some commodities must be purchased using cash [Lucas and Stokey (1983)]. Because there is no uncertainty, government bonds and productive capital yield the same rate of return.

The fiscal authority is assumed to issue bonds to finance its deficits. With overlapping generations, the economy is dynamically inefficient. In other words, the government can roll over the debt forever, which is a source of revenue for the government. The monetary authority is assumed to conduct open market operations to follow an interest-rate rule such as a Taylor rule. Because of AK technology, the real interest rate is constant over time, and therefore a Taylor rule reduces to a strict interest rate target, and this is a source of nominal indeterminacy.

It is shown that there are typically two Pareto-ranked balanced-growth equilibria, and that, because bonds and capital are competing assets, a higher rate of economic growth is associated with a lower level of public debt [Saint-Paul (1992)]. An important issue concerning the models that allow multiple equilibria is that it is not easy to determine which equilibrium is more reasonable. As pointed out by Evans et al. (1998), the standard stability analysis does not apply to a onesector endogenous growth model with multiple balanced-growth paths because the evolution of the output growth rate is governed entirely by the previous output growth rate, which leaves the dynamic system indeterminate. To put it differently, under perfect foresight, the model's initial condition (stated as a level of capital stock) cannot pin down a time path of the capital stock.

This note addresses the issue of equilibrium selection by employing the Estability principle, which claims that a rational expectations equilibrium is "reasonable" if it is approached under adaptive learning [Sargent (1993); Evans and Honkapohja (2001)]. For example, in the standard model of hyperinflation, the low-inflation steady state (which is Pareto superior to the other) is unstable under rational expectations, but is stable under adaptive learning, whereas the highinflation steady state is stable under rational expectations and unstable under learning [Sargent (1993)]. Recent applications of the E-stability principle in the context of policy interaction are found in Evans and Honkapohja (2007), which is concerned with the validity of the fiscal theory of the price level, and in Evans and Honkapohja (2005), which is concerned with the stability of the liquidity trap.

Interestingly, under a balanced budget, the two balanced-growth equilibria turn out to be E-stable, causing expectational indeterminacy [Evans et al. (1998)]. Furthermore, although fiscal policy can be used to overcome the problem of expectational indeterminacy, the selected equilibrium is Pareto dominated by the other. In other words, fiscal policy eliminates the high-welfare equilibrium, which contrasts with the previous result that adaptive learning selects the Pareto superior equilibrium [Moore (1993)]. Its policy implication is very important: the policy maker faces a trade-off between stabilization of private agents' expectations 
and output growth. In particular, ruling out expectational indeterminacy requires acceptance of a low rate of economic growth.

\section{THE MODEL}

\subsection{Environment}

Consider a growing economy consisting of an infinite sequence of two periodlived overlapping generations of individuals, the initial old generation, and an infinitely lived government. Let $t=1,2, \ldots$ index time. In each period, a new generation of unit measure is born. Each agent is endowed with one unit of labor when young and is retired when old. The initial old agents are endowed with $K_{1}>0$ units of capital, and receive $M_{0}$ units of fiat money from the central bank.

The production technology employed in this note is motivated by Bencivenga and Smith (1991) and Espinosa-Vega and Yip (1999). A single final good is produced using the production function $Y_{t}=A K_{t}^{\alpha}\left(k_{t} L_{t}\right)^{1-\alpha}$, where $A>0$, $1<\alpha<1, k_{t}$ is the aggregate capital stock, $K_{t}$ is the capital input, and $L_{t}$ is the labor input. The aggregate capital stock enters the production function because of the production externality: labor productivity rises as the society increases its stock of capital. In particular, $k_{t}=K_{t}$ in equilibrium. For expositional reasons, capital is assumed to depreciate $100 \%$ between periods.

Factor markets are perfectly competitive. Thus, factors of production receive their marginal product. I preclude agents' labor-leisure choices by assuming that young agents supply their labor endowment inelastically in the labor market. Thus, $L_{t}=1$ in equilibrium. When maximizing profits, firms take the aggregate stock of capital $k_{t}$ as given. Thus, $r_{t}=\alpha A k_{t}^{1-\alpha} K_{t}^{\alpha-1} L_{t}^{1-\alpha}=\alpha A$, and $w_{t}=$ $(1-\alpha) A k_{t}^{1-\alpha} K_{t}^{\alpha} L_{t}^{-\alpha}=(1-\alpha) A k_{t}=(1-\alpha) Y_{t}$.

\subsection{Households}

Let $c_{1 t}$ and $c_{2 t}$ denote a generation- $t$ agent's consumption when young and when old, respectively. To rule out an endogenous saving decision and to focus on individuals' portfolio choices, I assume that agents care about consumption only when old. In other words, $c_{1 t}=0$, so that all income is saved.

In this economy, there are three assets: money, government bonds, and capital. From the perspective of portfolio choice, there are three means of saving. It is well known that fiat money cannot coexist with interest-bearing assets unless money plays a role other than the store-of-value role. To describe an economy with multiple financial assets, I employ Lucas and Stokey's (1983) cash-in-advance model. In particular, consumption goods are divided into two types: "cash goods" and "credit goods." Cash goods must be purchased with cash. Thus, agents wishing to consume cash goods need cash in advance. On the other hand, agents do not need cash to purchase credit goods. Lucas and Stokey's (1983) interpretation is that at some stores, an agent is known to the producer and so credit is available, whereas at other stores, the agent is unknown to the seller and so cash must be 
used to make a transaction. Let $c_{m t}\left(c_{n t}\right)$ denote the amount of cash (credit) goods consumed when old. Then $c_{2 t}=c_{m t}+c_{n t}$ must hold, implying that the marginal rate of transformation between the two goods is unity. Thus, the price $p_{t}$ is the same for the two goods. The cash-in-advance constraint is given by

$$
p_{t+1} c_{m t} \leq M_{t}
$$

where $M_{t}$ denotes the nominal money balance. According to (1), a young agent must set aside cash in advance in order to purchase cash goods when old.

Agents may hold money, bonds, and capital. The budget constraints for young and old agents of generation $t$ are $M_{t}+B_{t}+p_{t} K_{t+1}=p_{t} w_{t}-T_{t}$ and $p_{t+1} c_{2 t}=$ $M_{t}+I_{t+1} B_{t}+p_{t+1} r_{t+1} K_{t+1}$, respectively. In real terms, these are written as

$$
\begin{aligned}
\frac{M_{t}}{p_{t}}+\frac{B_{t}}{p_{t}}+K_{t+1} & =w_{t}-\frac{T_{t}}{p_{t}}, \\
c_{2 t} & =\frac{p_{t}}{p_{t+1}} \frac{M_{t}}{p_{t}}+R_{t+1} \frac{B_{t}}{p_{t}}+r_{t+1} K_{t+1},
\end{aligned}
$$

where $R_{t+1} \equiv I_{t+1} p_{t} / p_{t+1}$ is the gross real interest rate on bonds. Absence of arbitrage opportunities in the asset market implies that bonds and capital have the same real rate of return. Thus, $R_{t+1}=r_{t+1}$. The cash-in-advance constraint binds if and only if money is (weakly) dominated by bonds and capital in rates of return. In other words, the cash-in-advance constraint binds if and only if $I_{t+1} \geq 1$.

Preferences are such that the agent cares only about his or her old-age consumption and derives utility from cash goods and credit goods. I specify the utility function as

$$
U\left(c_{m t}, c_{n t}\right)=\left[(1-\phi) c_{m t}^{1-\rho}+\phi c_{n t}^{1-\rho}\right]^{\frac{1}{1-\rho}}
$$

where $0<\phi<1$ and $\rho>0$. The elasticity of substitution between $c_{m t}$ and $c_{n t}$ is $1 / \rho$. Each young agent chooses $c_{m t}$ and $c_{n t}$ to maximize (4) subject to (1), (2), and (3). The first-order necessary conditions for the maximization problem require $U_{1} / U_{2}=I_{t+1}$, which gives the real money demand function $M_{t} / p_{t}=$ $\mu\left(I_{t+1}\right)\left(w_{t}-T_{t} / p_{t}\right)$, where $\mu(I) \equiv\left\{1+[\phi /(1-\phi)]^{\frac{1}{\rho}} I^{\frac{1-\rho}{\rho}}\right\}^{-1}$. It is easy to establish that $\mu(\cdot)$ satisfies $0<\mu(I)<1, \mu^{\prime}(I)<0$ for $\rho \in(0,1)$, and $I \mu^{\prime}(I) / \mu(I)=-[1-\mu(I)](1-\rho) / \rho$. Thus, as the nominal interest rate increases, the household substitutes away from money, which reduces money demand. An increase in the nominal rate, at the same time, raises the earnings from interestbearing assets, which raises money demand through the income effect. The former dominates the latter if $0<\rho<1$, in which case the elasticity of substitution between $c_{m t}$ and $c_{n t}$ is $1 / \rho>1$. On the other hand, with $\rho>1$, the elasticity is low and the income effect dominates.

Many other models generate a money demand function possessing the same properties. Hahn and Solow's (1997) cash-in-advance model assumes that a fixed fraction of old-age consumption must be purchased using cash. Here, the fraction 
is derived from the agent's utility maximization. The functional form (4) suggests that this is virtually a money-in-the-utility-function model. As pointed out by Carlstrom and Fuerst (2001), for determinacy of equilibria, it matters whether the real money balance at the beginning or the end of the transaction period enters the utility function. Because determinacy is an important issue in this note, I choose a model in which the issue of timing is not arbitrary to the model builder. Finally, the money demand function in this note is closely related to the reserve demand function in a random relocations model such as that in Espinosa-Vega and Yip (1999), where the demand for fiat money is determined by the banking sector. In this note, I assume no financial intermediation.

\subsection{Government}

Let $G_{t}$ denote government spending, $T_{t}$ denote the amount of tax revenue, $I_{t} \geq 1$ denote the gross nominal interest rate, and $B_{t}^{g}$ denote the amount of government bonds issued in period $t$. Then the fiscal authority's budget constraint is given by $G_{t}+I_{t} B_{t-1}^{g}=T_{t}+B_{t}^{g}$ for $t \geq 2$ and $G_{1}=T_{1}+B_{1}^{g}$ for $t=1$. The government has no initial debt obligation (i.e., $B_{0}^{g}=0$ ). I assume that the government simply consumes $G_{t}$ and that it does not affect the utility of any generation or the production process in any period. Divide the budget constraint by $p_{t} Y_{t}$, and use the Fisher equation, $R_{t+1} \equiv I_{t+1} p_{t} / p_{t+1}$, to obtain

$$
g_{t}=\tau_{t}+b_{t}^{g}-\frac{R_{t}}{\theta_{t}} b_{t-1}^{g},
$$

where $g_{t} \equiv G_{t} / p_{t} Y_{t}, \tau_{t} \equiv T_{t} / p_{t} Y_{t}, b_{t}^{g} \equiv B_{t}^{g} / p_{t} Y_{t}$, and $\theta_{t} \equiv Y_{t} / Y_{t-1}$. Because bonds and capital are competing financial assets in this economy, the no-arbitrage condition requires the rates of return on these assets to be the same in equilibrium. Thus, $R_{t}=r_{t}=\alpha A$.

Consider the central bank. If $B_{t}^{m}$ denotes the monetary authority's demand for government bonds, then the budget constraint for the central bank is $B_{t}^{m}=$ $I_{t} B_{t-1}^{m}+M_{t}-M_{t-1}$ for $t \geq 2$, and $B_{1}^{m}=M_{1}-M_{0}$ for $t=1$. Divide this by $p_{t} Y_{t}$ to obtain

$$
b_{t}^{m}=\frac{R_{t}}{\theta_{t}} b_{t-1}^{m}+m_{t}-\frac{p_{t-1}}{p_{t}} \frac{1}{\theta_{t}} m_{t-1},
$$

where $b_{t}^{m} \equiv B_{t}^{m} / p_{t} Y_{t}$ and $m_{t} \equiv M_{t} / p_{t} Y_{t}$.

To capture the recent practice of monetary policy making, the central bank is assumed to follow an interest-rate rule rather than controlling the monetary base. In particular, $I_{t}=I^{*}\left(\Pi_{t} / \Pi^{*}\right)^{\lambda}$, where $I^{*}$ and $\Pi^{*}$ are the implicit targets for $I_{t}$ and $\Pi_{t}$, respectively, and $\lambda$ is a nonnegative parameter that captures the degree of aggressiveness of monetary policy. It is important to note that $R_{t}=\alpha A$ and the Fisher equation imply

$$
I_{t}=\alpha A \Pi_{t}=\alpha A \Pi^{*}\left(I_{t} / I^{*}\right)^{\frac{1}{\lambda}} \Leftrightarrow I_{t}=\left(\alpha A \Pi^{*}\right)^{\frac{\lambda}{\lambda-1}}\left(I^{*}\right)^{\frac{1}{1-\lambda}} .
$$


In other words, an interest-rate rule is equivalent to a strict targeting of the nominal interest rate. This is also equivalent to a strict targeting of the rate of inflation. This occurs because the real interest rate is constant in this one-sector AK growth model. Because the exact form of the monetary policy rule does not matter, for brevity, in what follows I let $I_{t}=I$ for all $t .^{1}$

The bond market equilibrium requires $B_{t}+B_{t}^{m}=B_{t}^{g}$ or $b_{t}+b_{t}^{m}=b_{t}^{g}$. Thus, (5) and (6) are integrated into the consolidated government budget constraint

$$
g_{t}=\tau_{t}+b_{t}-\frac{R_{t}}{\theta_{t}} b_{t-1}+m_{t}-\frac{p_{t-1}}{p_{t}} \frac{1}{\theta_{t}} m_{t-1}
$$

for $t \geq 2$, and $g_{1}=\tau_{1}+b_{1}+m_{1}-M_{0} / p_{1} Y_{1}$ for $t=1$. For brevity, I assume that $g_{t}=g$ and $\tau_{t}=\tau$ for all $t$. Further, I assume that $g<1$ (which guarantees $\left.G_{t}<p_{t} Y_{t}\right)$ and $\tau<1-\alpha$ (which guarantees $\left.T_{t}<p_{t} w_{t}\right)$.

\section{PERFECT-FORESIGHT BALANCED-GROWTH EQUILIBRIA}

A monetary equilibrium under perfect foresight is defined as a set of sequences for real allocations $\left\{m_{t}, b_{t}, k_{t}\right\}$, relative prices $\left\{R_{t}, \Pi_{t}\right\}$, the initial price level $p_{1}$, and initial conditions $k_{1}>0, M_{0} \geq 0$, and $B_{0}=0$, such that each household maximizes utility, asset markets and factor markets both clear, the fiscal and monetary authorities' budget constraints are both satisfied, fiscal policy specifies $g$ and $\tau$, and monetary policy specifies $I$. In what follows, I look for a balancedgrowth equilibrium, in which all per GDP variables stay the same.

The money market equilibrium is described as $M_{t} / p_{t}=\mu(I)\left[w_{t}-T_{t} / p_{t}\right]$. Divide this by $Y_{t}$ to obtain

$$
m_{t}=(1-\alpha-\tau) \mu(I)
$$

Similarly, the market equilibrium for capital is given by $k_{t+1}+B_{t} / p_{t}=w_{t}-$ $T_{t} / p_{t}-M_{t} / p_{t}$. Divide this by $Y_{t}$ to obtain

$$
\frac{\theta_{t+1}}{A}+b_{t}=(1-\alpha-\tau)[1-\mu(I)]
$$

Finally, substitute (9) and (10) into the government budget constraint (8) to obtain

$$
\theta_{t+1}=(1-g) A-\frac{(1-\alpha-\tau) \alpha A^{2} h(I)}{\theta_{t}} \equiv \Omega\left(\theta_{t}\right)
$$

for $t \geq 2$, where $h(I) \equiv 1-\mu(I)+\mu(I) / I>0$. Equation (11) describes the law of motion of the economy written entirely in terms of the rate of output growth. A balanced-growth equilibrium is defined as a state in which the output growth rate $\theta_{t}$ is constant over time. It is easy to establish that function $\Omega$ satisfies $\Omega^{\prime}(\theta)=$ $(1-\alpha-\tau) \alpha A^{2} h(I) \theta^{-2}>0, \lim _{\theta \rightarrow 0} \Omega^{\prime}(\theta)=\infty$, and $\lim _{\theta \rightarrow \infty} \Omega^{\prime}(\theta)=0$. In addition, $\lim _{\theta \rightarrow \infty} \Omega(\theta)=(1-g) A$ implies that the output growth rate is bounded by $(1-g) A$. 


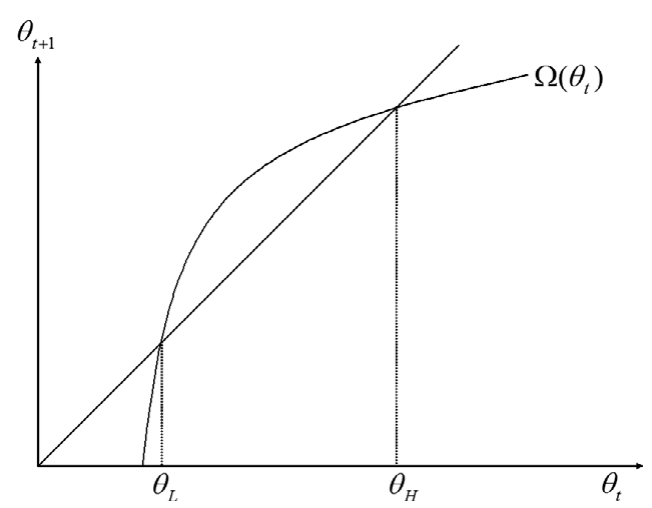

FigURE 1. Balanced-growth equilibria.

From (11), the balanced-growth equilibria solve the quadratic equation $\theta^{2}-$ $(1-g) A \theta+(1-\alpha-\tau) \alpha A^{2} h(I)=0$. The roots are

$$
\theta=\frac{1-g \pm \sqrt{(1-g)^{2}-4 \alpha(1-\alpha-\tau) h(I)}}{2 / A},
$$

which are real if and only if $(1-g)^{2}>4 \alpha(1-\alpha-\tau) h(I)$. Thus,

PROPOSITION 1. (a) There exist two distinct balanced-growth equilibria if $(1-g)^{2}>4 \alpha(1-\alpha-\tau) h(I)$, (b) there exists a unique balanced-growth equilibrium if $(1-g)^{2}=4 \alpha(1-\alpha-\tau) h(I)$, and (c) there exists no balanced-growth equilibrium if $(1-g)^{2}<4 \alpha(1-\alpha-\tau) h(I)$.

Figure 1 depicts the balanced-growth equilibria of the model. The high-growth equilibrium is denoted by $\theta_{H}$, and the low-growth equilibrium is denoted by $\theta_{L}$. It is evident that $\Omega^{\prime}\left(\theta_{L}\right)>1>\Omega^{\prime}\left(\theta_{H}\right)$. Multiple steady states are commonly observed in models in which seigniorage is used to finance a fixed primary deficit [Espinosa-Vega and Yip (1999); Sargent (1999)]. This is because of the presence of a hump-shaped Laffer curve, in which there is a tension between higher inflation tax rate and lower inflation tax base. Espinosa-Vega and Yip (1999) showed that, in an endogenous growth model with money, there is a unique balanced-growth equilibrium if agents are sufficiently risk-averse. Here, the multiplicity result is independent of agents' preferences.

This economy also possesses a Laffer curve, but it is rather unconventional:

$$
\begin{gathered}
g-\tau=\underbrace{\left(1-\frac{R}{\theta}\right)\left\{(1-\alpha-\tau)[1-\mu(I)]-\frac{\theta}{A}\right\}}_{\text {Revenue from issuing bonds }} \\
+\underbrace{\left(1-\frac{1}{\Pi \theta}\right)(1-\alpha-\tau) \mu(I)}_{\text {Revenue from money creation }} \equiv \Phi(\theta),
\end{gathered}
$$




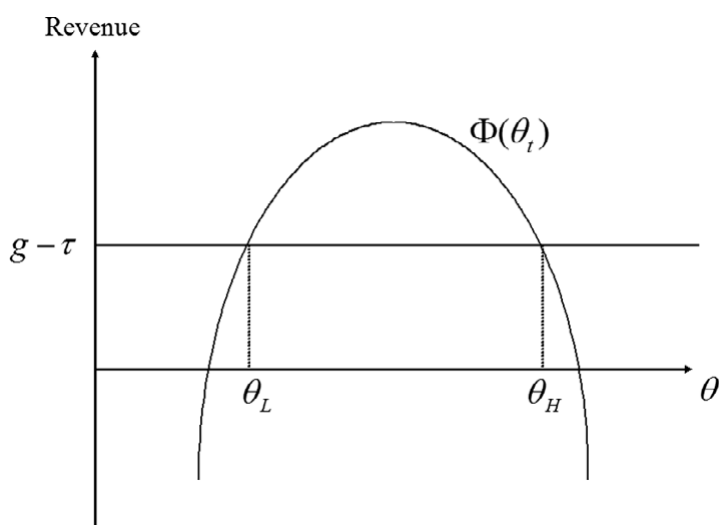

FigURE 2. Growth-rate Laffer curve.

where it is easy to establish that $\Phi^{\prime}(\theta)>0 \Longleftrightarrow \Omega^{\prime}(\theta)>1$. In other words, this "growth-rate Laffer curve" is upward sloping at $\theta_{L}$ and downward sloping at $\theta_{H}$, as depicted in Figure 2.

Because the government issues bonds and the central bank prints money, the Laffer curve has two components, the revenue from issuing government bonds and seigniorage. Two points are new. One is that, because an overlapping generations economy can support a dynamically inefficient equilibrium, the government in this economy can roll over the debt forever to make a positive revenue from bonds. The other is that this Laffer curve $\Phi(\theta)$ describes the relationship between the output growth rate (rather than the inflation tax rate) and government revenue. ${ }^{2}$ In other words, it states how economic growth will contribute to the government's revenue.

Consider the shape of this Laffer curve. The second term suggests that seigniorage is increasing in the output growth rate. Thus, currency seigniorage does not cause multiple equilibria. Nonmonotonicity is introduced by the first term, the revenue from issuing bonds. The mechanism is as follows. An increase in the output growth rate reduces the government's debt services, thereby increasing the government's revenue. However, an increase in the output growth rate must be financed by an increase in investment, which decreases the demand for government bonds. This is the major force that generates nonmonotonicity and multiple equilibria.

PROPOSITION 2. The high-growth equilibrium Pareto-dominates the lowgrowth equilibrium.

Proof. From (1), $c_{m t}=m_{t} Y_{t} p_{t} / p_{t+1}$. Similarly, (1), (2), and (3) imply $c_{n t}=$ $R_{t+1} B_{t} / p_{t}+r_{t+1} K_{t+1}=R_{t+1}\left(B_{t} / p_{t}+K_{t+1}\right)=R_{t+1}\left(w_{t}-T_{t} / p_{t}-M_{t} / p_{t}\right)$. Thus, in any balanced-growth equilibrium, $c_{m t}=(\mathrm{m} / I) R Y_{t}$ and $c_{n t}=\left(w_{t} / Y_{t}-\right.$ $\tau-m) R Y_{t}=(1-\alpha-\tau-m) R Y_{t}$. It is then easy to rewrite (4) as $U_{t}=(1-\alpha-$ $\tau) \alpha A \Theta(I) Y_{t}$, where $\Theta(I) \equiv\left\{(1-\phi)[\mu(I) / I]^{1-\rho}+\phi[1-\mu(I)]^{1-\rho}\right\}^{1 /(1-\rho)}>0$. 
I follow Espinosa-Vega and Yip (1999) in defining welfare as $W \equiv \sum_{t=1}^{\infty} \beta^{t-1} U_{t}$, where $\beta<1$ is the discount factor. Note that, at any balanced-growth equilibrium, aggregate output evolves according to $Y_{t+1}=\theta Y_{t}$, which can be solved for $Y_{t}$ as $Y_{t}=\theta^{t-1} Y_{1}$. Thus,

$$
W=(1-\alpha-\tau) \alpha A^{2} \Theta(I) k_{1} \sum_{t=1}^{\infty}(\beta \theta)^{t-1}
$$

Suppose that $\beta$ is sufficiently small so that $\beta \theta<1$. In that case, (14) is well defined and can be rewritten as $W=(1-\alpha-\tau) \Theta(I)(1-\beta \theta)^{-1} \alpha A^{2} k_{1}$. It is then easy to verify that $W$ is increasing in $\theta$.

I now analyze the effects of changes in the policy parameters on the rates of growth and inflation at the balanced-growth equilibria.

PROPOSITION 3. (a) An increase in $g$ increases (decreases) $\theta$ and decreases (increases) $b$ at the low-growth (high-growth) equilibrium. (b) An increase in $\tau$ decreases (increases) $\theta$ at the low-growth (high-growth) equilibrium.

Proof. (a) Consider Figure 1. An increase in $g$ shifts the $\Omega$ locus downward. Thus, $\theta$ increases (decreases) at the low-growth (high-growth) equilibrium. Because $b=(1-\alpha-\tau)[1-\mu(I)]-\theta / A$ implies a negative relationship between $b$ and $\theta, b$ decreases (increases) at the low-growth (high-growth) equilibrium. (b) Evident from (12). An increase in $\tau$ unambiguously decreases $b$ at $\theta_{H}$, but the effect is ambiguous at $\theta_{L}$.

The intuition for Proposition 3a is as follows. An increase in $g$ induces the government to raise more revenue. Because the "growth-rate Laffer curve" $\Phi(\theta)$ is increasing at the low-growth equilibrium, the government needs to promote economic growth to finance the increased deficit. As a result, agents reduce their bond holdings and invest more. In other words, a higher deficit crowds capital in. In contrast, because the Laffer curve is decreasing at the high-growth equilibrium, the government issues more bonds to crowd out capital, reducing the output growth rate. According to Proposition 3b, a deficit-financed permanent tax cut does not generate enough government revenue to justify the increase in the deficit. As a result, a permanent tax cut works in the same manner as a permanent increase in $g$.

LEMMA 4. $h^{\prime}(I)<0$ holds if $(1-\rho) I<1$.

Proof. Because $h(I) \equiv 1-\mu(I)+\mu(I) / I>0$, it is easy to show that

$$
\begin{aligned}
& h^{\prime}(I)=-\frac{I-1}{I} \frac{\mu(I)}{I}\left[\frac{1}{I-1}+\frac{I \mu^{\prime}(I)}{\mu(I)}\right] \\
& =-\frac{I-1}{I} \frac{\mu(I)}{I}\left\{\frac{1}{I-1}-\frac{1-\rho}{\rho}[1-\mu(I)]\right\} .
\end{aligned}
$$


It is evident that $(1-\rho) I<1$ implies $(I-1)^{-1}>(1-\rho) / \rho$. Because $\mu(I) \geq 0$ and $0<\rho<1$ imply $(1-\rho) / \rho \geq[1-\mu(I)](1-\rho) / \rho$ for any $I \geq 1$, it follows that $(I-1)^{-1}-(1-\rho) / \rho>0$ implies $(I-1)^{-1}-[1-\mu(I)](1-\rho) / \rho>0$. Thus, $h^{\prime}(I)<0$ holds if $(1-\rho) I<1$.

Throughout, $\rho$ is assumed to satisfy $(1-\rho) I<1$. With this lemma, it is easy to establish the growth effects of monetary policy. Totally differentiate (11) to obtain $d \theta / d I=(\partial \Omega / \partial I) /\left[1-\Omega^{\prime}(\theta)\right]$, where $\partial \Omega / \partial I=-(1-\alpha-\tau) \alpha A^{2} h^{\prime}(I) / \theta>0$. The sign of $1-\Omega^{\prime}(\theta)$ is negative at the low-growth equilibrium and is positive at the high-growth equilibrium. Thus,

PROPOSITION 5. An increase in I (which is associated with an increase in П) reduces (increases) the output growth rate at the low-growth (high-growth) equilibrium.

An increase in $I$ shifts the $\Omega$ locus up in Figure 1. Thus, an increase in $I$ reduces (increases) $\theta$ at the low-growth (high-growth) equilibrium. The intuition is as follows. An increase in the nominal interest rate induces agents to substitute money for interest-bearing assets. However, this does not necessarily promote economic growth. In this AK economy, an increase in the nominal interest rate implies an increase in the rate of inflation. Because these two effects have offsetting impacts on currency seigniorage, the overall effect on currency seigniorage is ambiguous. On the other hand, an increase in the nominal interest rate increases the demand for bonds, and it increases the revenue from issuing government bonds. Overall, less revenue is needed. Because the "growth-rate Laffer curve" is increasing at $\theta_{L}$, the growth rate is reduced to finance the deficit. Similarly, because the growth-rate Laffer curve is decreasing at $\theta_{H}$, the growth rate must be raised to finance the deficit.

PROPOSITION 6. The low-growth equilibrium is unstable and locally determinate. The high-growth equilibrium is stable and locally indeterminate.

The dynamics of $\theta_{t+1}=\Omega\left(\theta_{t}\right)$ is easily checked using Figure 1 . The low-growth (high-growth) equilibrium is unstable (stable) under perfect foresight because the $\Omega$ locus cuts the $45^{\circ}$ line from below (above). In addition to the existence of two balanced-growth equilibria, there are infinitely many rational expectations paths leading to the stable balanced-growth equilibrium from any given initial condition $k_{1}$. The root of indeterminacy is the model's inability to supply the initial conditions. To see this, rewrite the dynamics $\theta_{t+1}=\Omega\left(\theta_{t}\right)$ as $k_{t+1} / k_{t}=$ $\Omega\left(k_{t} / k_{t-1}\right)$, which is a second-order difference equation about $k_{t}$ : to start the economy, one must supply two initial conditions, $k_{1}$ and $k_{2}$, and only $k_{1}$ can be supplied exogenously.

Can the model supply $k_{2}$ endogenously? The capital market equilibrium in period 1 is $k_{2}+B_{1} / p_{1}=w_{1}-T_{1} / p_{1}-M_{1} / p_{1}$, and the consolidated budget constraint in period 1 is $G_{1}-T_{1}=B_{1}+M_{1}-M_{0}$. It follows that $k_{2}=w_{1}-$ $G_{1} / p_{1}-M_{0} / p_{1}=(1-\alpha-g) A k_{1}-M_{0} / p_{1}$, which may be used to determine 
$k_{2}$ if the initial price level $p_{1}$ is known. The money market equilibrium in period $1, m_{1}=(1-\alpha-\tau) \mu(I)$, only determines the real money balance, leaving the initial price level undetermined. ${ }^{3}$

The intuition for the indeterminacy result is as follows. As (10) suggests, $k_{2}+B_{1} / p_{1}=(1-\alpha-\tau)[1-\mu(I)] A k_{1}$. Thus, with initial capital, the young in period 1 chooses the amount of saving that is allocated to capital and bonds. The agent's capital investment can be determined once $B_{1} / p_{1}$ is determined. In a nonmonetary economy, the real debt in period 1 is determined by the government's primary deficit in that period. In this monetary economy, the level of real debt is determined by the primary deficit minus the currency seigniorage. However, with $p_{1}$ undetermined, the size of the currency seigniorage cannot be determined. Hence, $B_{1} / p_{1}$ and therefore $k_{2}$ is left undetermined. As a result, nominal indeterminacy translates into real indeterminacy. ${ }^{4}$

\section{LEARNING EQUILIBRIA}

The standard method of equilibrium selection under multiple steady states is to apply stability analysis. However, as Evans et al. (1998) pointed out, one cannot apply standard stability analysis to a model with multiple rates of output growth. This is because the dynamic system (11) is written entirely by $\theta_{t}$. As a consequence, for any initial value of capital, "the economy can select either of the perfect-foresight paths" [Evans et al. (1998, p. 500)]. Here, I adopt an adaptive learning scheme as an equilibrium selection device [Evans et al., (1998); Evans and Honkapohja (2001)].

The basic idea is to consider the behavior of the economy outside of the perfectforesight equilibria and to ask to which equilibrium agents' expectations converge. Following Evans and Honkapohja (2001), I assume the adaptive learning scheme

$$
\theta_{t+1}^{e}=\theta_{t}^{e}+\gamma_{t+1}\left(\theta_{t-1}-\theta_{t}^{e}\right)
$$

where $\theta_{t+1}^{e}$ is a point expectation of the next period's output growth rate. $\gamma_{t}=\gamma / t$ is called the "gain sequence" in the learning literature. If $\gamma_{t}$ were constant, then (15) would imply that agents form adaptive expectations. It is sometimes said that information is lagged if the adaptive learning scheme is described by (15). Alternatively, one could replace the learning rule with $\theta_{t+1}^{e}=\theta_{t}^{e}+\gamma_{t+1}\left(\theta_{t}-\theta_{t}^{e}\right)$, which corresponds to the case in which information is current. In the literature, it is normally assumed that information is lagged because the use of current information causes simultaneous interactions between $\theta_{t}$ and $\theta_{t}^{e}$ [Van Zandt and Lettau (2003)].

In the standard models of adaptive learning, agents learn to form expectations about the future interest rate because the portfolio choice depends on the future interest rate. As is clear from (15), in this economy, the agents form expectations about the output growth rate [see also Alonso-Carrera (2001)]. The reason is as follows. In this AK economy, both the real and nominal interest rates are known to 
all agents. Thus, for portfolio choice between monetary and nonmonetary assets, there is no need to form expectations about interest rates. However, to determine the allocation of the nonmonetary assets between government bonds and productive capital, it is necessary to form expectations about the growth rate.

Consider a temporary equilibrium. From (9), $m_{t}=(1-\alpha-\tau) \mu(I)$ for all $t$. Similarly, from (10),

$$
b_{t}=(1-\alpha-\tau)[1-\mu(I)]-\theta_{t+1}^{e} / A,
$$

which asserts that the real demand for bonds is determined once a point expectation about the future output growth rate is formed. Interestingly, the demand for government bonds shrinks as agents expect the economy to grow more rapidly. Similarly, if $\theta_{t+1}^{e}$ is low, then agents wish to hold more government bonds, a phenomenon frequently observed during a recession.

Substitute (16) into the government's budget constraint (8) to obtain the actual output growth rate as a function of $\theta_{t+1}^{e}$ and $\theta_{t}^{e}$,

$$
\theta_{t}=\frac{(1-\alpha-\tau) \alpha A^{2} h(I)-\alpha A \theta_{t}^{e}}{(1-\alpha-g) A-\theta_{t+1}^{e}} \equiv F\left(\theta_{t+1}^{e}, \theta_{t}^{e}\right) \text {, }
$$

which states that the actual time- $t$ growth rate is determined so that it is consistent with the real demand for bonds, the point expectation on the output growth rate, and the government budget constraint. Note that it does not need to coincide with the rational expectations value. Agents revise expectations using (15) and form a point expectation of the time- $(t+2)$ growth rate. The mapping from the perceived law of motion to the actual law of motion is therefore given by

$$
\frac{(1-\alpha-\tau) \alpha A^{2} h(I)-\alpha A \theta}{(1-\alpha-g) A-\theta} \equiv H(\theta) .
$$

The differential equation for characterizing expectational stability, or E-stability, of the system is given by $d \theta / d s=H(\theta)-\theta$, where $s$ is "notional" or "virtual" time [Evans and Honkapohja (2001)]. To see this, substitute (17) into (15) to obtain $\theta_{t+1}^{e}=\theta_{t}^{e}+\gamma_{t+1}\left[F\left(\theta_{t}^{e}, \theta_{t-1}^{e}\right)-\theta_{t}^{e}\right]$, which is a second-order system in the expected output growth rate. Let $\Delta=\gamma_{t+1}$ and rewrite it as $\theta_{t+\Delta}^{e}=\theta_{t}^{e}+\Delta\left[F\left(\theta_{t}^{e}, \theta_{t-\Delta}^{e}\right)-\theta_{t}^{e}\right]$, or $\left(\theta_{t+\Delta}^{e}-\theta_{t}^{e}\right) / \Delta=F\left(\theta_{t}^{e}, \theta_{t-\Delta}^{e}\right)-\theta_{t}^{e}$. Notice that $\lim _{t \rightarrow \infty} \Delta=0$. It follows therefore the differential equation $d \theta^{e} / d s=H\left(\theta^{e}\right)-\theta^{e}$, where $H\left(\theta^{e}\right)=\lim _{t \rightarrow \infty} F\left(\theta_{t}^{e}, \theta_{t-1}^{e}\right)$. The condition for E-stability is therefore $H^{\prime}\left(\theta^{e}\right)<1$. A remarkable feature of the E-stability principle is that the adaptive system converges to a rest point of $H\left(\theta^{e}\right)=\theta^{e}$ with probability one if $H^{\prime}\left(\theta^{e}\right)<1$ is satisfied at the rest point [Evans and Honkapohja (2001)].

PROPOSITION 7. (a) The low-growth equilibrium is E-stable, and (b) the high-growth equilibrium is E-stable if and only if $g<(1-\alpha) \mu(I)(I-1) / I+$ $\tau h(I)$. 


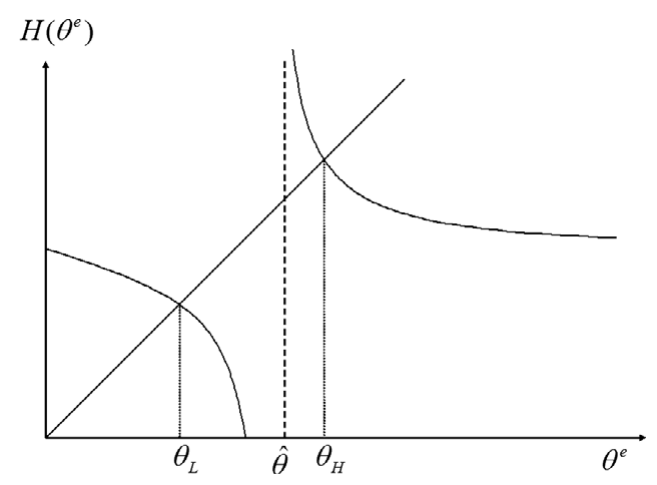

FigURE 3. E-stable equilibria.

Proof. It is easy to verify that $H^{\prime}(\theta)=\alpha A^{2}[(1-\alpha-\tau) h(I)-(1-\alpha-$ $g)] /[(1-\alpha-g) A-\theta]^{2}$. Thus, $H^{\prime}(\theta)<0$ for all $\theta$ if and only if $g<(1-$ $\alpha) \mu(I)(I-1) / I+\tau h(I)$. The configuration of the map $H$ depends on the sizes of $g$ and $\tau$. If $g<(1-\alpha) \mu(I)(I-1) / I+\tau h(I)$, then, as shown in Figure 3, there are two distinct fixed points, and the curve cuts the $45^{\circ}$ line from above at both equilibria. In this case, both equilibria are E-stable. It is easy to see that $\lim _{\theta \rightarrow \hat{\theta}} H^{\prime}(\theta)=-\infty$ and $\lim _{\theta \rightarrow \infty} H^{\prime}(\theta)=0$, where $\hat{\theta} \equiv(1-\alpha-g) A$. If, on the other hand, $g>(1-\alpha) \mu(I)[I-1] / I+\tau h(I)$ holds, then, as shown in Figure 4, $H(\theta)$ is increasing. There are two distinct fixed points, and the curve cuts the $45^{\circ}$ line from above (below) at the low-growth (high-growth) equilibrium. It is easy to verify that $\lim _{\theta \rightarrow \hat{\theta}} H^{\prime}(\theta)=\infty$.

Interestingly, for sufficiently small levels of government spending, both of the balanced-growth equilibria, $\theta_{L}$ and $\theta_{H}$, are E-stable. Sargent (1993) and more recently McCallum (2007) pointed out that there is an important link between determinacy of perfect foresight (or rational expectations) equilibria and stability

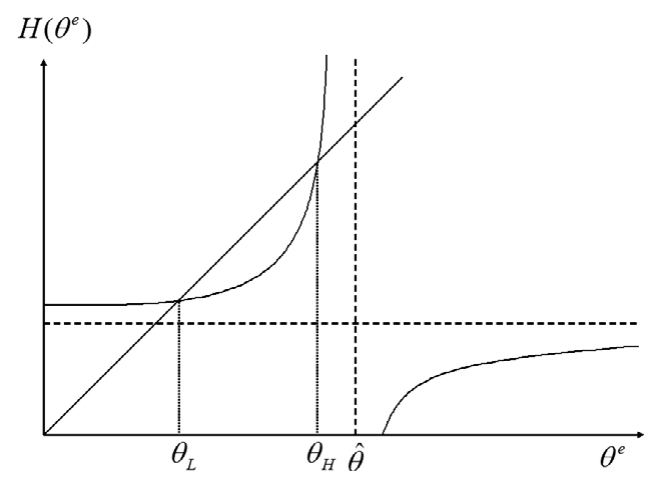

FIGURE 4. Unique E-stable equilibrium. 
under adaptive learning. In this economy, the high-growth, indeterminate equilibrium can also be E-stable. Because there are two E-stable equilibria, it is no longer possible to select an equilibrium under learning. This corresponds to the case of expectational indeterminacy [Evans et al. (1998)]. For sufficiently large values of $g$, the low-growth equilibrium is the only E-stable equilibrium. In other words, fiscal policy can eliminate expectational indeterminacy. However, the high-welfare equilibrium is ruled out. Also interesting is that a change in $g$ does not change the determinacy property of the model, but it may change the E-stability of the model.

COROLLARY 8. Under a balanced budget $(g=\tau>0)$, both of the balancedgrowth equilibria, $\theta_{L}$ and $\theta_{H}$, are E-stable.

Proof. Let $g=\tau$. The high-growth equilibrium is E-stable if and only if $\tau<(1-\alpha) \mu(I)(I-1) / I+\tau h(I) \Longleftrightarrow \tau<1-\alpha$, which holds by construction.

According to Proposition 7, whether or not the high-growth equilibrium is Estable depends on $g, \tau, I$, and the money demand function. However, under a balanced budget, the high-growth equilibrium is always E-stable, causing expectational indeterminacy. This finding is somewhat similar to that of Schmitt-Grohé and Uribe (2000), who argued that a balanced-budget policy does not eliminate indeterminacy of monetary equilibrium. Evans et al. (2007) also found that a balanced-budget policy does not eliminate sunspot equilibria under learning.

COROLLARY 9. Near the lower bound of the nominal interest rate (i.e., $I \approx$ 1 ), the high-growth equilibrium is E-stable if and only if $g<\tau$.

This result can easily be verified by noticing that $h(1)=1$. The implication of this result is that, if the economy stays near the lower bound of the nominal interest rate, then even a small primary deficit will select the low-growth equilibrium to be the unique E-stable equilibrium.

\section{CONCLUDING REMARKS}

This note has studied an endogenous growth model with multiple assets. There are two balanced-growth equilibria under perfect foresight, which are both Estable under a balanced budget. Fiscal policy can be used to pin down a learning equilibrium, but the low-growth, Pareto-dominated equilibrium is selected; the cost of ruling out expectational indeterminacy is low economic growth. The benefit of reducing fiscal spending is to make the high-growth equilibrium valid and to boost economic growth at the cost of expectational indeterminacy.

An important limitation of the analysis is that it adopts a highly stylized model: the real interest rate is constant because of AK technology, and the nominal interest rate is constant because of the interest-rate rule. To study the robustness of the results obtained in this note, one needs to extend the model, along the lines of Itaya and Mino (2004) and Benhabib and Wen (2004), to allow the real interest 
rate to be variable. It is also important to allow the interest-rate feedback rule to be forward-looking or backward-looking to study how the timing of the rule might affect the learnability of the balanced-growth equilibria.

The "growth-rate Laffer curve" found in this note clarifies how economic growth finances the government's budget deficit. Particularly important is the finding that higher economic growth does not always finance a larger deficit because it requires more investment funds, leading to a lower demand for government bonds. Important future work is to investigate the government's incentive to promote economic growth when the government simultaneously needs to raise more revenue.

\section{NOTES}

1. Suppose that $I_{t}=I^{*}\left(\Pi_{t+1} / \Pi^{*}\right)^{\lambda}$, under which the central bank reacts to the future inflation rate. Then $I_{t+1}=\left(I^{*}\right)^{-1 / \lambda}\left(\alpha A \Pi^{*}\right) I_{t}^{1 / \lambda}$. Similarly, suppose that $I_{t}=I^{*}\left(\Pi_{t-1} / \Pi^{*}\right)^{\lambda}$, under which the central bank reacts to the lagged inflation rate. Then $I_{t}=I^{*}\left(\alpha A \Pi^{*}\right)^{-\lambda} I_{t-1}^{\lambda}$. In either case, the nominal interest rate in the balanced-growth equilibrium is the same as in (7), whereas their dynamic implications depend on the timing and whether monetary policy is active $(\lambda>1)$ or passive $(\lambda<1)$. Here, it is sufficient to point out that the dynamic properties of the system are not invariant to the timing of feedback rules.

2. Kudoh (2007) studied a Laffer curve written in terms of the nominal interest rate.

3. According to the fiscal theory of the price level, the initial price level can be determined if there is a unique initial price level that is consistent with a unique steady state. This does not apply to this economy because there are multiple steady states.

4. It is interesting to observe that, with a positive level of initial nominal debt $\left(B_{0}>0\right)$, the same indeterminacy result would arise even with $M_{0}=0$. In other words, what is central for indeterminacy here is the presence of the initial nominal wealth.

\section{REFERENCES}

Alonso-Carrera, Jaime (2001) "On learning to forecast in an endogenous growth model with externalities. Journal of Economic Dynamics and Control 25, 1139-1156.

Bencivenga, Valerie R. and Bruce D. Smith (1991) Financial intermediation and endogenous growth. Review of Economic Studies 58, 195-209.

Benhabib, Jess and Yi Wen (2004) Indeterminacy, aggregate demand, and the real business cycle. Journal of Monetary Economics 51, 503-530.

Carlstrom, Charles T. and Timothy S. Fuerst (2001) Timing and real indeterminacy in monetary models. Journal of Monetary Economics 47, 285-298.

Espinosa-Vega, Marco A. and Chong K. Yip (1999) Fiscal and monetary policy interactions in an endogenous growth model with financial intermediaries. International Economic Review 40, 595613.

Evans, George W. and Seppo Honkapohja (2001) Learning and Expectations in Macroeconomics. Princeton, NJ: Princeton University Press.

Evans, George W. and Seppo Honkapohja (2005) Policy interaction, expectations and the liquidity trap. Review of Economic Dynamics 8, 303-323.

Evans, George W. and Seppo Honkapohja (2007) Policy interaction, learning, and the fiscal theory of prices. Macroeconomic Dynamics 11, 665-690.

Evans, George W., Seppo M.S. Honkapohja, and Ramon Marimon (2007) Stable sunspot equilibria in a cash-in-advance economy. B.E. Journal of Macroeconomics 7(1), (Advances), Article 3.

Evans, George W., Seppo Honkapohja, and Paul Romer (1998) Growth cycles. American Economic Review 88, 495-515. 
Hahn, Frank and Robert Solow (1997) A Critical Essay on Modern Macroeconomic Theory. Cambridge, MA: MIT Press.

Itaya, Jun-ichi and Kazuo Mino (2004) Interest-rate rule and multiple equilibria with endogenous growth. Economics Bulletin 5, 1-8.

Kaas, Leo and Gerd Weinrich (2003) Money and growth in a production economy with multiple assets. Macroeconomic Dynamics 7, 670-690.

Kudoh, Noritaka (2007) Low nominal interest rates: A public finance perspective. International Journal of Central Banking 3, 61-93.

Lucas, Robert E., Jr. and Nancy Stokey (1983) Optimal fiscal and monetary policy in an economy without capital. Journal of Monetary Economics 12, 55-93.

McCallum, Bennett T. (2007) E-stability vis-a-vis determinacy results for a broad class of linear rational expectations models. Journal of Economic Dynamics and Control 31, 1376-1391.

Moore, Bartholomew J. (1993) Least-squares learning and the stability of equilibria with externalities. Review of Economic Studies 60, 197-208.

Saint-Paul, Gilles (1992) Fiscal policy in an endogenous growth model. Quarterly Journal of Economics 107, 1243-1259.

Sargent, Thomas J (1993) Bounded Rationality in Macroeconomics. Oxford: Oxford University Press.

Sargent, Thomas J (1999) A primer on monetary and fiscal policy. Journal of Banking and Finance 23, 1463-1482.

Schmitt-Grohé, Stephanie and Martín Uribe (2000) Price level determinacy and monetary policy under a balanced-budget requirement. Journal of Monetary Economics 45, 211-246.

Van Zandt, Timothy and Martin Lettau (2003) Robustness of adaptive expectations as an equilibrium selection device. Macroeconomic Dynamics 7, 89-118. 